\title{
Review \\ Ocular Manifestations of Behçet's Disease: An Update on Diagnostic Challenges and Disease Management
}

\author{
Hanna Zając ${ }^{1, *}$ and Anna Turno-Kręcicka ${ }^{1,2, *}$ \\ 1 Department of Ophthalmology, University Clinical Hospital in Wroclaw, 50-556 Wroclaw, Poland \\ 2 Department of Ophthalmology, Wroclaw Medical University, 50-556 Wroclaw, Poland \\ * Correspondence: zajhanna@gmail.com (H.Z.); turno@autograf.pl (A.T.-K.)
}

check for updates

Citation: Zając, H.; Turno-Kręcicka, A. Ocular Manifestations of Behçet's Disease: An Update on Diagnostic Challenges and Disease Management. J. Clin. Med. 2021, 10, 5174. https:// doi.org/10.3390/jcm10215174

Academic Editors: Massimo Cesareo and Fumi Gomi

Received: 21 September 2021 Accepted: 3 November 2021 Published: 5 November 2021

Publisher's Note: MDPI stays neutral with regard to jurisdictional claims in published maps and institutional affiliations.

Copyright: (c) 2021 by the authors. Licensee MDPI, Basel, Switzerland. This article is an open access article distributed under the terms and conditions of the Creative Commons Attribution (CC BY) license (https:/ / creativecommons.org/licenses/by/ $4.0 /)$.

\begin{abstract}
Behçet's disease is a systemic vasculitis that affects multiple organs. The most common manifestations are oral and genital ulcerations and recurrent uveitis. Uveitis can be an initial symptom in $10-20 \%$ of cases and leads to blindness in $16-25 \%$ of patients. The management of this disease is evolving due to the clinical phenotypes recently described in the literature and increasing focus on the detection of subclinical inflammation to enable correct therapeutic decisions. The first line treatment is azathioprine, followed by various immunosuppressive and biological agents as alternatives in severe or refractory cases. This review summarizes scientific articles about the etiology of, diagnostic tools for and treatment of the ocular manifestations of Behçet's disease available in the PubMed database from 1 January 2016 to 1 May 2021. A multidisciplinary approach is necessary to effectively prevent permanent damage and thus improve the life quality of the patients. Therefore, it is crucial to raise awareness of the common clusters of symptoms, use of modern imaging methods, such as ocular computed tomography and fluorescein angiography, and novelty treatment algorithms to enable early diagnosis and appropriate management.
\end{abstract}

Keywords: Behçet's disease; ocular Behçet; uveitis; management of Behçet's disease

\section{Introduction}

Behçet's disease (BD) is a chronic, multi-system, relapsing vasculitis of unknown etiology. It affects both genders at a different ratio depending on the region, but mostly is predominant in male [1]. The typical time of onset is between the second and the fourth decade of life. Nevertheless, it may also start in childhood (4-26\% incidence) [2] or at an older age. It is mainly sporadic; however, there have been some familial cases, suggesting a complex inheritance model of the disease. Mucocutaneous aphthous lesions in the oral cavity and genital area and recurrent uveitis are the most common symptoms. Death rate is approximately $5 \%$ in 5-10 years [3], especially due to cardiovascular or central nervous system (CNS) complications. The prognosis is poorer for male patients with a younger age of onset $[1,4,5]$ and multiple manifestations at the time of diagnosis $[2,3,6,7]$.

$\mathrm{BD}$ is one of the most severe causes of noninfectious uveitis and occurs in up to $50-90 \%$ of patients [3,8-10]. Behçet's uveitis (BU) can lead to blindness that affects 16-25\% [10] of patients within 5-10 years after onset [11]. BU develops usually after 2-3 years [8]; however, there may be an initial presentation of this systemic disease $(10-20 \%)[3,8,9]$.

The highest prevalence of BD is reported in the Middle East and East Asia. The exact prevalence in Poland is unknown; however, it is believed to be underdiagnosed [12] (Table 1).

According to a genome-wide association study Human Leukocyte Antigen, B51 (HLA-B51) is the strongest genetic/endogenous factor in BD. Between $40 \%$ and $80 \%$ of patients with BD have HLA-B51, whereas it is present only in $10-30 \%$ of healthy controls. For this reason its detection is valuable information, even though it is not a part of the official diagnostic criteria [16]. Moreover, patients with HLA-B51 are more prone to developing ocular manifestations of $\mathrm{BD}$. A strong correlation is observed in regions towards the east, along 
the ancient Silk Road in Eurasia; however, it is not statistically significant in Europe [16,17]. HLA-A26 carriers have a higher risk of developing iridocyclitis and retinochoroiditis, although its impact is more prominent for men [18].

Table 1. Epidemiology of Behçet's disease.

\begin{tabular}{cc}
\hline Region & Prevalence Rate per 100,000 Inhabitants \\
\hline Turkey & $20-420[13]$ \\
Iran & $80-100[14]$ \\
Northern Europe & $0.3-4.9[13]$ \\
Sweden & $2.3-4.9[13]$ \\
Germany & $0.3-4.87[13,15]$ \\
England & $0.27-0.64[13]$ \\
Southern Europe & $1.5-15.9[2,13]$ \\
Italy & $3.8-15.9[13]$ \\
Spain & $7.5[13]$ \\
France & $7.1[13]$ \\
Portugal & $1.53[13]$ \\
United States & $5.2[14]$ \\
\hline
\end{tabular}

The results of a nationwide survey in Germany corroborate the role of genetic background of $\mathrm{BD}$. The prevalence of $\mathrm{BD}$ among patients of Turkish origin living in Germany was similar to that reported from Western Turkey $(20-80 / 100,000)$, while the prevalence in Germany $(0.3 / 100,000)$ was comparable to other North European regions [15]. Populationbased prevalence studies in France have found that immigrants of North African and Asian ancestry have a similar prevalence of $\mathrm{BD}$ to the countries of their origin. Moreover, the prevalence of $\mathrm{BD}$ is not influenced by the age of the individual at the time of immigration, which strongly supports the hereditary basis of the disease [19]. Kötter et al. compared patients with BD of Turkish origin living in Germany with those living in Turkey, and with German patients. The authors did not reveal any differences that would support the influence of ethnicity on the expression of $\mathrm{BD}$, which stands in contrast to the previously mentioned studies. They proposed that the higher frequency of ocular manifestations and a higher male to female ratio in Turkish patients living in Germany compared to those living in Turkey may be due to environmental factors [20]. A study by Shahram et al. comparing a selected group of US patients with Iranian and Turkish patients revealed some interesting findings. Even though there was a higher proportion of women in the US group, US patients had more severe presentations of the disease than the Iranian and Turkish patients. The American patients were more often diagnosed with multi-organ manifestations and were less prone to developing ocular vasculitis. On the contrary, the Iranian patients were more likely to present with a single-organ disease and were at higher risk for ocular vasculitis. This may be caused by milder cases being underdiagnosed in the United States [14]. The authors believe that ocular and extra-ocular BD may follow independently regulated pathogenesis, as well as differing according to the geographical and genetic background of the patient $[7,14]$.

A retrospective study by Hussein et al. conducted on an Egyptian cohort (249 patients) revealed a total of $51 \%$ of cases with ocular involvement. Patients presented with anterior $(59 \%)$ and posterior uveitis $(74.8 \%)$, panuveitis $(33.8 \%)$, retinal vasculitis $(31.4 \%)$, papillitis $(7.8 \%)$ and chorioretinitis $(54.3 \%)$, macular edema $(9.4 \%)$ and secondary retinal detachment $(7.8 \%)$. A total of $74.01 \%$ of cases were classified as having a vision-threatening disease (VTD). It has been found that the absence of the systemic criteria (genital ulcers, systemic vasculitis and, maybe oral ulcers as well) may mean that the eye is at higher risk for the development of VTD [21].

Multidisciplinary collaboration is essential for treatment, as it depends on the current organ involvement and factors, such as age, gender, type and severity of symptoms and disease duration. The goal is to develop targeted therapies, prevent relapses and suppress inflammation [7]. 
The aim of this review is to focus on the management of the ocular manifestation of $\mathrm{BD}$ that are described in the literature.

\section{Materials and Methods}

This review was prepared by using the database of PubMed. Articles from peerreviewed journals published from 1 January 2016 to 1 May 2021 were chosen using the following search words: ocular Behçet, and uveitis Behçet. This was followed by manual searches based on articles cited in the texts of other articles. We included articles contributing to the topics of the epidemiology, diagnosis, and treatment of ocular manifestations of Behçet's disease. Clinical studies were selected if they were randomized controlled trials, single- or double-blind, or interventions with pharmacological therapy compared to placebo or some other pharmacological agents or unrandomized studies with valuable remarks for future investigation. Abstracts were used in the case of non-English articles. All of the figures used in the articles have been obtained from the authors' clinic.

\section{Results}

\subsection{Etiopathogenesis}

There are probably several pathways of pathogenesis-there is an interplay of genetic susceptibility factors with unbalanced immune homeostasis. Positive responses to immunosuppressive agents, the involvement of autoantigens, and antigen-specific T-cells suggest an autoimmune background. Seemingly unprovoked episodes of inflammation may indicate an autoinflammatory origin [22,23]. It shares some features of a spondyloarthropathy, based on the association with HLA-B51, epistatic endoplasmic reticulum aminopeptidase 1 (ERAP-1) interactions, increased T helper (Th) 17 response, and neutrophilic involvement [22,23]. However, infectious agents have been proposed as a trigger of BD development [2]. Cross reaction of microbial antigens and human proteins may lead to a pathological immune response in genetically predisposed individuals. Herpes simplex virus 1 and bacteria of the Streptococcus species (among others, Streptococcus sanguinis and Streptococcus pyogenes) has shown evidence of the highest correlation with BD [22,23]. It is speculated that oral microbial flora plays a role in the pathogenesis of BD, as it usually starts in the oral mucosa and tends to flare up after dental and surgical procedures in the oral cavity. It has been reported that BD patients have less diverse salivary and gut microbial flora in comparison to healthy controls [23].

Retinal pericytes, which may influence the intravascular immunity, are of the same origin as the CNS pericytes and may function differently from the peripheral vascular pericytes. Hussein et al. suggest the possibility of having two immunological variants of BD (with central and peripheral impact), which corresponds with the findings of the abovementioned study by Shahram et al. [14,21].

\subsection{Diagnostic Criteria}

The most common classification criteria for the diagnosis are International Criteria for Behçet's Disease (ICBD) and the International Study Group (ISG) criteria. In a study comparing the ICBD 2006, revised ICBD 2010, ISG criteria and revised Japanese criteria, it was found that the ICBD 2010 had the highest sensitivity (98.83\%), negative predictive value $(98.48 \%)$, diagnostic odds ratio (1645), and Youden's index (0.94), and the lowest negative likelihood ratio (0.01) [24].

\section{ICBD Criteria}

- Ocular lesions (uveitis, retinal vasculitis, chorioretinitis, papillitis) — two points;

- Oral aphthosis of at least three times/year-two points;

- Recurrent genital aphthosis-two points;

- Skin lesions (papulopustular rash, erythema nodosum) - one point;

- CNS lesions (parenchymal CNS involvement, venous sinus thrombosis)_one point; 
- Vascular manifestations (venous thromboembolism, superficial thrombophlebitis, arterial thrombosis, aneurysm — especially aortic and pulmonary)—one point;

- $\quad$ The positive pathergy test-one point;

- A patient scoring $\geq 4$ points is classified as having BD [24].

\subsection{Extra-Ocular Manifestations}

Oral aphthae are often a presenting sign of BD. They are round, painful ulcerations with a diameter of 2-15 mm. They last for 7-10 days and heal with no scarring, unless large. Painful genital ulcerations appear mostly on the scrotum and labia and are similar to the oral ulcerations. They are usually bigger, deeper and are more likely to heal with scarring.

The most common skin lesions are recurrent erythema nodosum, papulopustular lesions on upper torso and extremities and folliculitis-like lesions. Nearly 40\% [6] of the patients present with pathergy positive $\mathrm{BD}$, although it is not pathognomonic for $\mathrm{BD}$ and may not be present when the patient is already under systemic immunosuppressive treatment $[7,12,17]$.

Arthritis develops in up to 50\% [6] of patients. It is usually monoarticular, non-erosive, and self-limiting, with attacks lasting a few weeks. Intestinal BD manifests as ulcers of the esophagus, stomach, and intestines $[6,7,25]$.

Vascular involvement occurs in $25 \%$ [6] of patients. It varies from the superficial vein to the superior/inferior vena cava thrombosis, vessel occlusion, and arterial aneurysms. Cardiac complications include pericarditis, granulomatous endocarditis, myocarditis, coronary arteritis, myocardial fibrosis, and intracardiac thrombosis. Pulmonary artery aneurysm is one of the most lethal complications and is considered to be almost pathognomonic for $\mathrm{BD}[6,7,25]$.

Neuro-Behçet's Syndrome occurs in $5-10 \%$ [7,25] of BD patients, mostly $(75-80 \%)$ [7] affecting the CNS. Neurological involvement poses a great threat to the patient, as lesions of the white matter of the brain and brainstem may lead to motor dysfunction, cognitive and behavior changes and stroke. Neuroophthalmological findings, such as cranial nerve palsies, papillitis and papilledema may occur due to the thrombosis of the venous sinuses $[6,7,25]$.

\subsection{Ocular Manifestations}

Behçet's uveitis is defined as a chronic relapsing bilateral nongranulomatous panuveitis and retinal vasculitis [9]. BU can affect both the anterior and the posterior segment of the eye; however, panuveitis is the most frequent presentation [26]. Only $10 \%$ of patientsmost of whom are women-present with an isolated anterior uveitis $[25,27]$.

Occlusive necrotizing retinal vasculitis is a critical component of BU [28]. In fundoscopy, periphlebitis has the form of perivascular diffuse white haziness [9] and may be accompanied by periarteriolitis, which never occurs alone [2,28]. Thrombotic incidents are typically bilateral inflammatory branch retinal vascular occlusions. They lead to arteriolar attenuation and retinal non-perfusion, followed by retinal neovascularization [29], which is a possible source of retinal hemorrhage [2] (Figure 1) or even hemorrhagic periphlebitis [9]. After the resolution of the acute inflammatory process, the eye fundus may present with sheathed ghost vessels [9]. Frosted branch angiitis, with or without neuroretinitis, is another possible manifestation [9].

Breakage of the blood-retinal barrier due to inflammation results in perifoveal capillary leakage that causes cystoid macular edema (CME) and further macular structural changes. Vascular leakage is observed within the optic disc, peripheral retina, and macula $[10,14,26,29]$. CME is diagnosed in up to $60 \%$ of BU cases [30] and poses a potential threat of vision loss $[2,9,26,28,29,31,32]$.

Vitreous haze is a sign of an active inflammation in the posterior pole. Vitritis is most prominent at the beginning of the attack and dissolves gradually [2,27], causing a relapsing visual blurring [9]. A pathognomonic sign for BU is inferior, pearl-like peripheral 
inflammatory precipitates organized in a linear pattern after 4-7 days from the uveitis onset that disappear without any sequel within weeks [2,32].

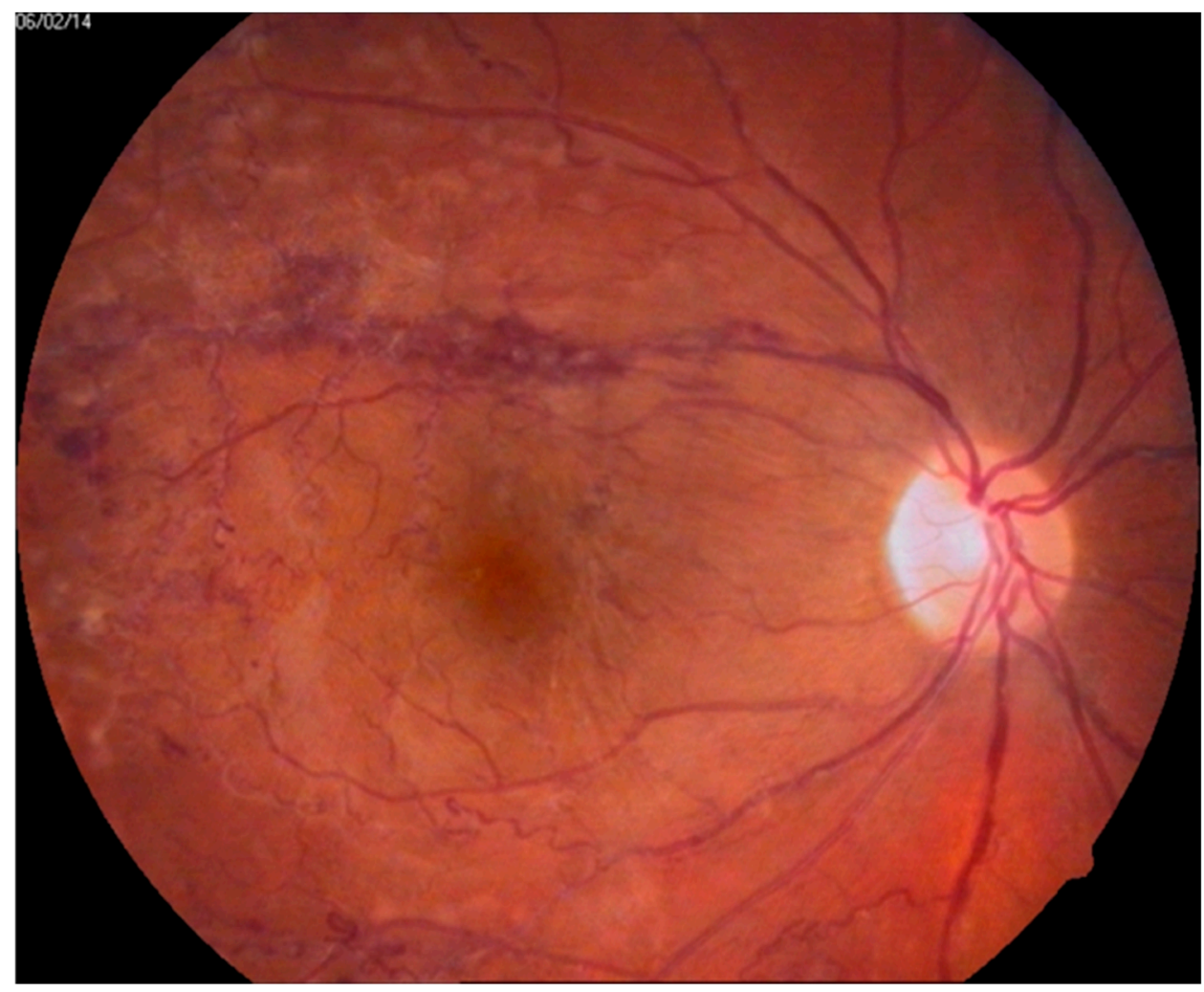

Figure 1. Color eye fundus photographs of patients with Behçet's Disease. Fundus presents with vascular changes of the superior arcade, widened, irregular and tortuous veins, intraretinal hemorrhages and premacular inflammatory fibrosis.

Hypopyon is a poor prognostic factor [7] that has been long considered a hallmark of $\mathrm{BU}$, although nowadays is known to be a rather nonspecific sign [1,9]. It is present in only $30-40 \%$ of cases [29]. A characteristic feature of BU is a lack of fibrinous exudate in the anterior chamber. Therefore, the hypopyon is non-sticky and can move freely with gravity $[27,29,33]$. Even though spontaneous remission within days to weeks is a known natural course of BU [32], it is unlikely to be observed in the clinical practice, as patients almost always receive intense treatment [27,33]. Anterior segment inflammation usually presents with mild or no ciliary injection, diffuse endothelial dusting and normal or low intraocular pressure [2,9]. Absence of mutton-fat keratic precipitates, chronic cells and chronic high-grade flare is typical for BU [9].

Severe BU results in retinal atrophy with clear vitreous, optic and macular atrophy, diffuse atrophy and gliosis of the retina with sheathed and attenuated cord-like white retinal vessels, which can mimic retinitis pigmentosa [9].

\subsection{Diagnostic Tools}

\subsubsection{Spectral Domain Optical Coherence Tomography (SD OCT)}

SD OCT can be a screening tool for posterior involvement in Behçet's uveitis. Superficial retinal infiltrates or their sequels are the most common finding in the fundus during active inflammation. They present as white patches that do not obscure underlying vessels and disappear within days with no scarring [9]. In the SD OCT they present as a focal, hyper-reflective thickening of the retina, blurring of the inner retinal layers and optical shadowing without thickening of the underlying choroid. The retinal pigment epithelium is not disrupted [2,27]. A wedge-shaped retinal nerve fiber layer defect and thinning are possible sequels of the retinal infiltrates $[2,9,32]$. Localized vitreous condensation over the 
inflamed optic disc characteristically forms a "smoking volcano" shape in SD OCT [28], which can be used to observe the regression of the vitreous haze over the optic nerve in neuroretinitis [2,27].

The mean central macular thickness (CMT) and macular volume (MV) are increased in eyes with Behçet's posterior uveitis and panuveitis, even in the absence of macular edema [28]. Therefore, the use of fluorescein angiography (FA) may be targeted for cases with the highest suspicion of posterior uveitis [28]; however, it still remains the gold standard in the monitoring of $\mathrm{BU}$, as OCT does not visualize the retinal vasculature $[2,27,32]$. Kang et al. have reported a decrease in CMT and MV after 2-3 months of treatment, which suggests the value of SD OCT as an additional monitoring tool [28]. Enhanced deep imaging OCT (EDI OCT) is another complementary examination for the detection of the subclinical ocular and systemic inflammation that can be indicated by increased choroidal thickness in an eye without clinically active uveitis [34].

Gürlü et al. performed a study comparing OCT findings in BD patients in uveitis remission and healthy individuals. A significant decrease of central macular thickness (CMT), decreased parafoveal Ganglion Cell Complex (GCC) and increased perifoveal GCC thickness was found in the remission group. CMT decreases with the number of uveitis attacks. The authors speculated that the GCC perifoveal thickness increases due to the occlusive changes in the superficial capillaries and local limited ischemia and may decrease later as a consequence of cell loss, which had already happened in the parafoveal area [26].

Optical coherence tomography angiography (OCTA) generates three-dimensional images of ocular fundus vasculature. Emre et al. recommend this method to visualize microvascular changes in patients with BU and other forms of uveitis. They found areas of hypoperfusion and nonperfusion in both deep capillary plexus (DCP) and superficial capillary plexus (SCP); however changes in DCP were more prominent than those in SCP. Moreover, the capillary vessel density was significantly lower in patients with BU than in the control group, and foveal avascular zone (FAZ) was reported to be larger in patients with BU. According to the authors, OCTA is superior to fluorescein angiography (FA) in terms of evaluating FAZ [35].

Zarei et al. claim peripapillary OCT to be a quantitative non-invasive method of assessing ocular inflammation that can serve as an alternative to FA, reducing the sessions of FA acquisition. Although FA remains the modality of choice to determine the extent of retinal vasculitis in $\mathrm{BD}$, its strong dependence on the examiner may interfere with a standardized interpretation and comparison. For each micron increase in peripapillary retinal nerve fiber layer thickness (PNFLT), there was an 0.008 increase in logMAR and thus a deterioration of visual acuity. The authors draw attention to the fact that a conventional format of the OCT data output is set to detect "thinning", not "thickening", and therefore there is no color-coding to differentiate a thickened PNFL from a normal PNFL [36].

\subsubsection{Fluorescein Angiography}

The advantage of the fluorescein angiography (FA) over angio-OCT is the ability of the former to visualize the whole fundus, while OCTA is limited to the posterior pole. Therefore, FA enables the detection of peripheral areas of insufficient perfusion that would benefit from laser photocoagulation [32]. In the FA, patients with occlusive and diffuse vasculitis present with fern-like peripheral leakage, optic disc and posterior pole leakage (Figure 2), engorgement and tortuosity of the veins and staining of the vessel walls [2,27,32]. A total vascular leakage score has been proposed to evaluate the course of uveitis, that is a sum of scores for the lesions at the disc, macula and peripheral retina in both eyes. The extent of leakage is described by points $(0=$ none, $1=$ mild, $2=$ moderate, $3=$ severe) [29]

Chams et al. investigated a group of 50 patients (100 eyes) that had no apparent ocular signs in either biomicroscopy or fundoscopy. The study revealed that $44 \%$ of patients had leakage of fluorescein at the peripheral retina in both eyes in the FA, mostly from the final branches. Moreover, four of them presented leakage from the optic disc and one from the posterior pole. In the infrared autofluorescence of the fundus, $86 \%$ of patients presented 
with modified hypo- and hyper-autoreflectivity. This may be secondary to changes in the pigmentary cells and vascular modifications in the choroid. A total of $50 \%$ of patients presented with aberrant retinal vascular branching: either tortuous, straightened or with a vascular shunt [31]. FA may be useful for early diagnosis and the prompt introduction of treatment, as suppressing chronic subclinical inflammation is important to prevent complications $[2,6,31,32]$.

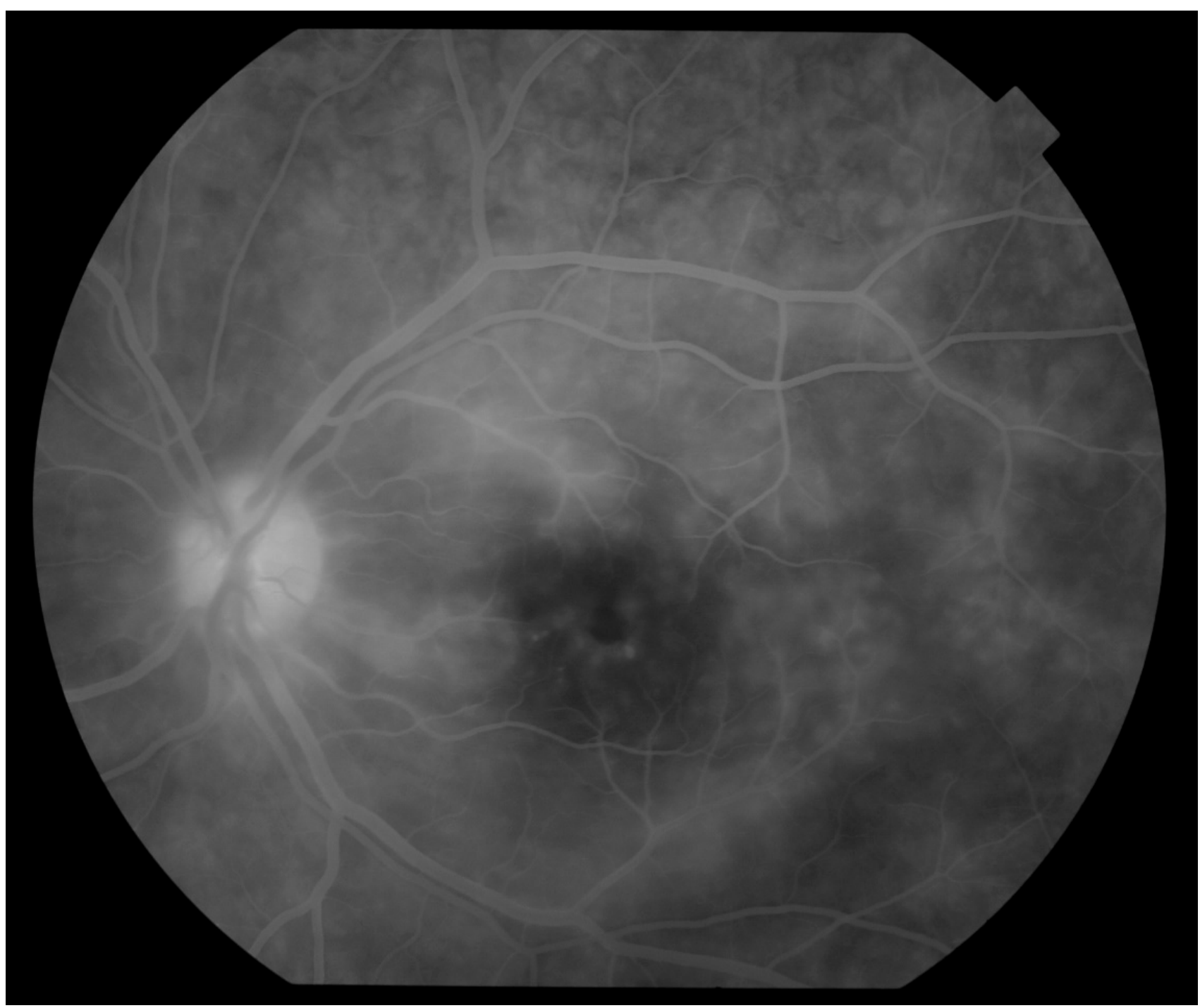

Figure 2. Fluorescein angiography of a patient with Behçet's uveitis with cystoid macular edema, venous leakage, leakage from the cilioretinal artery and optic disc edema.

Conventional fundus cameras can caption $30^{\circ}$ to $60^{\circ}$ view of the fundus at a time, while a recently introduced ultra-wide-field (UWF) imaging system provides $200^{\circ}$ photographic, autoflourographic and angiographic view of the ocular fundus. UWF images may contribute to a more accurate detection of disease activity and appropriate disease management. In a prospective study comparing clinical decisions in cases of noninfectious retinal vasculitis, treatment was changed after $10 \%$ of visits based on clinical examination or standard fluorescein angiography, and after a further $24 \%$ of visits with UWF color photography and 51\% of visits based on UWF fluorescein angiography [37]. 


\subsubsection{Other Diagnostic Methods}

Laser flare-cell photometry (LFCP) is an objective method used to quantify flare and cell count in the anterior chamber (AC). Its use is limited because of a possible overestimation of cell count due to other particles in the AC, such as pigment discharge or red blood cells. The measurements are also unreliable in cases of very high grade of inflammatory cells or any particular matter in the AC [38]. Tugal-tutkun et al. investigated the use of LFCP in patients with BD. They reported no increase in flare in patients without ocular involvement, while it was significantly higher in patients during ocular attack or in remission. There was a significant correlation between FA leakage and AC flare. Moreover, the risk of recurrent uveitis attack was significantly higher in eyes with flare values $>6$ photons $/ \mathrm{msec}$ than in eyes with flare below this value. They claim that LFCP is a reliable method to monitor ocular inflammation in BD, which can decrease the need for FA and may be useful in clinical trials due to its quantitative outcomes [39].

Even though the indocyanine green angiography (ICGA) may present some nonspecific changes, dark dots representing choroidal granulomas are never found [9]. ICGA appears not to add further clinically relevant information about BD, other than differential diagnosis towards granulomatous anterior uveitis or choroiditis [9] and detection of central serous retinopathy as a side effect of a high-dose CS therapy [32].

Optic neuritis without intraocular inflammation is a part of neuro-BD [40]. It can result in visual acuity loss and impaired color vision. Mahgoub et al. have conducted visual evoked potential (VEP) examination in patients with BD with no recent ocular manifestation. They have reported a statistically significant positive correlation between p100 latencies and BD activity scores that decreased after steroid treatment for other active lesions, which may suggest subclinical visual pathway involvement [41]. Taking into consideration the point that ocular and neurological manifestations of $\mathrm{BD}$ are believed to coexist as a part of one phenotype [42], VEP may serve as a tool in the search of subclinical neurological involvement in ocular BD.

The chronic inflammatory process in BU has been reported to influence the cornea $[43,44]$. Cankaya and Kalayci have found an increase in the central corneal thickness and corneal resistance factor during uveitis attacks [43], whereas Ozbek-Uzman et al. reported a decrease in corneal thickness (CT) and corneal volume (CV) during an inactive period. $\mathrm{CV}$ and CT were significantly correlated with the frequency of previous uveitis attacks. The corneal changes were found to be independent from the location of uveitis [43]. These changes may be explained by endothelial pump and barrier dysfunction during the active period [44] and the stimulation of apoptosis and degradation of the fibrils by the inflammatory molecules present in the anterior chamber during remission [43].

A significant decrease of Tear Break-Up Time $[45,46]$ and increased frequency of squamous conjunctival metaplasia and goblet cell loss [46] have been reported in patients with ocular BD. However, ocular BD has not been associated with quantitative Meibomian gland changes [46].

Behçet's disease ocular attack score 24 (BOS24) is a novelty scoring system, designed to evaluate the activity of ocular inflammation in BU [47]. The BOS24 summarizes points given according to the following symptoms during an active uveitis episode: anterior chamber cells ( $0-4$ points), vitreous opacity ( $0-4$ points), peripheral fundus lesions $(0-8$ points), posterior pole lesions ( $0-4$ points), subfoveal lesions ( $0-2$ points) and optic disc lesions (0-2 points) [47]. The authors believe that the results of all of the attacks over five years (BOS24-5Y) are a more reliable characteristic of disease activity than only the frequency of relapses [47]. Keino H. consider this to be an objective and quantitative method and believe it to be a valuable tool to determine the timing of initiation and withdrawal of the treatment with anti-TNF agents [29].

\subsection{Differential Diagnosis}

The most important differential diagnosis to be considered are briefly summarized in Table 2. 
Table 2. Differential diagnosis of Behçet's disease ocular manifestations.

\begin{tabular}{|c|c|}
\hline Differential Diagnosis & Characteristic Features \\
\hline Sarcoidosis & $\begin{array}{l}\text { Intermediate uveitis, snowballs, focal retinal leakage, choroidal nodules, iris } \\
\text { nodules, optic disc nodules, mutton-fat keratic precipitates, } \\
\text { segmental/nodular periphlebitis (candle-like drippings) [48] }\end{array}$ \\
\hline Tuberculosis & $\begin{array}{l}\text { Usually associated with anterior segment inflammation, peripheral ischemia, } \\
\text { snowballs, perivascular choroidal scars, broad-based posterior synechiae, } \\
\text { serpiginous-like choroiditis }[9,49]\end{array}$ \\
\hline Syphilis & $\begin{array}{l}\text { Iritis, iridocyclitis, wedge shaped, ground-glass retinitis with inner retinal } \\
\text { precipitates, chorioretinitis, placoid lesions at the level of retinal pigmented } \\
\text { epithelium [50] }\end{array}$ \\
\hline Viral retinitis & $\begin{array}{l}\text { Massive necrotizing retinitis, CMV: absence of intense vitreous haze with } \\
\text { severe retinitis [9] }\end{array}$ \\
\hline Toxoplasmosis & Granulomatous keratic precipitates, hypertensive anterior uveitis [9] \\
\hline HLA-B27-associated acute anterior uveitis & Slow response to topical steroids, fibrinous exudate, sticky hypopyon [9] \\
\hline Primary intraocular lymphoma and leukemia & Smooth-layered hypopyon with mild ciliary injection [9] \\
\hline
\end{tabular}

\subsection{Treatment}

$\mathrm{BD}$ is a multidisciplinary entity, the division of which can be approached in different manners. Several clusters of BD manifestations have been identified, such as: "the mucocutaneous and articular phenotype", "the extra-parenchymal neurological and peripheral vascular phenotype" and "the parenchymal neurological and ocular phenotype" [42,51]. Uveitis was not significantly correlated with neurological manifestations in a BD phenotype analysis in China; however, it was suggested that parenchymal involvement was rare across the race and ethnicity of the cohort [52]. Bettiol et al. suggest that BD treatment should be targeted at clusters of symptoms instead of focusing on each presentation separately [42].

Both the anterior and the posterior segment of the eye can be affected by inflammation; however controlling the posterior uveitis is the most crucial factor to preserve the best possible visual acuity [26]. There have been developed various therapy schemes of local, and systemic treatment that depend on the affected structures and severity of the disease [7].

Isolated anterior uveitis can be treated with topical corticosteroid (CS) drops at a high initial frequency [2,22], tapered to stop after 6-8 weeks [2,22]. Mydriatic and/or cycloplegic drops should be administered 2-3 times a day for 2-3 weeks [2]. In case of poor prognostic factors, systemic immunosuppressive treatment with AZA is indicated [7].

\subsubsection{Corticosteroids}

Acute posterior uveitis exacerbations should be treated aggressively due to the potential threat of severe vision loss. The treatment of severe cases of the ocular and parenchymal neurological phenotype should be induced with high-dose corticosteroids (CSs), followed by gradual tapering over 3-6 months [42]. Acute posterior uveitis attack should be treated with intravenous pulse methyl prednisolone (IVPM) 250-1000 mg for 1-3 days, followed by oral $1 \mathrm{mg} / \mathrm{kg} /$ day with slow tapering - until the maintenance dose of $\leq 7.5 \mathrm{mg}$ [49] is reached or with a high oral dose $(1-1.5 \mathrm{mg} / \mathrm{kg} /$ day) $[53,54]$. IVPM are believed to prevent visual loss in acute phase of $\mathrm{BU}$, and they are followed by less complications than a long period of therapy with high-dose CSs [54]. CSs should be always used together with immunosuppressive agents as a bridging therapy $[2,7,25,27,54-56]$.

Intravitreal or periocular CS injections are suggested to be an effective adjuvant therapy in a unilateral disease, refractory CME, in patients with contraindications to systemic CSs or when an adequate response to the systemic therapy is not achieved [14,55]. According to the study of Yalcinbayir et al., in which a dexamethasone intravitreal implant $(0.7 \mathrm{mg})$ was injected to the eyes with $\mathrm{CME}$ in $\mathrm{BU}$, the highest visual gain was reached within the first two months following the injection, and $48 \%$ of eyes gained at least three lines of 
visual acuity [30]. However, possible complications, such as cataracts (7.4-36\%), increased intraocular pressure (14.8-43\%) and glaucoma ( $9 \%$ ), should be taken into consideration [30]. It has been reported that a single-dose infliximab infusion is more efficient in suppressing acute episodes than intravenous or intravitreal CSs and may serve as an alternative [7,30].

\subsubsection{Immunosuppressive Treatment}

European League Against Rheumatism (EULAR) have issued in 2018 an update of the recommendations for the treatment of $\mathrm{BD}$. Azathioprine (AZA) and cyclosporine-A (CsA) have the highest level of evidence and strength of recommendation for patients with posterior uveitis [55].

Azathioprine is reported in the literature to be effective in the treatment of $\mathrm{BU}$ in the dose of p.o. 2-2.5 mg/kg per day [7,42]. Bettiol et al. consider it an adequate induction treatment for the ocular and parenchymal neurological phenotype [42]. AZA decreases the rate of hypopyon uveitis and new eye disease [7] and furthermore preserves visual acuity and prevents relapses [55]. AZA and IFN-alpha should not be combined due to the risk of myelosuppression [11].

Cyclosporin-A (CsA) (p.o. $5 \mathrm{mg} / \mathrm{kg} /$ day) is proven to decrease the frequency and severity of relapses in $\mathrm{BU}[7,55]$. However, the use of CsA is contraindicated in the active neuro-BD [55] and therefore should not be implemented in the "parenchymal neurological and ocular phenotype" [42,57]. An increased prevalence of CNS manifestations has been reported in patients under this drug [58].

Bettiol et al. imply cyclophosphamide (CYC) $(1 \mathrm{~g} /$ month for six months and then every two to three months) to be the third line treatment for the ocular and parenchymal phenotype [42].

Mycophenolate mofetil (500 mg-2 g/day) [5] and methotrexate (7.5-20 mg/week) [5] have been suggested to be alternative immunosuppressive options.

\subsubsection{Biological Treatment}

According to EULAR reccomendations stated in 2018 biological treatment should be used as the second line treatment, as its efficacy was not supported by any randomized controlled study by the time of the update [55]. They outline that interferon-alpha, infliximab (IFX) and adalimumab (ADA) are preferred by some experts for the management of patients who are refractory to AZA and CsA [55].

The Ocular Immunology and Uveitis Foundation have stated that BD with retinal involvement is an absolute indication for an early use of immunomodulatory therapy. They stress its importance in the cases of sight-threatening uveitis and for patients who are refractory to corticosteroids [59]. Interferon alpha (IFN-alpha) and anti-tumor necrosis factor (TNF) agents, such as infliximab (IFX) and adalimumab (ADA), are widely recommended as first or second-line treatment options for refractory and/or recurrent cases $[2,7,42,55,56,60-64]$. The choice of the immunomodulatory therapy depends on the severity of inflammation and on the time in which the drug provides therapeutic effect (Figure 3).

In a review by Thomas A.S., the use of ADA and IFX is indicated as the first-line therapy of uveitis in $\mathrm{BD}$, whereas for most other noninfectious uveitis entities these drugs remain a second choice [62].

Levy-Clarke et al. have given a strong recommendation of a panel of experts based on an extensive review of literature from 2014 about the use of anti-TNF agents in the therapy of BD. They suggest that IFX and ADA are adequate for first- or second-line corticosteroidsparing therapy with ocular BD. Moreover, IFX may be a first- or second-line treatment for acute exacerbations of pre-existing BD [65]. This corresponds with the algorithm of treatment of BD uveitis by Karadag et al. from 2020, that included IFX or IFN-alpha as first-line therapy for acute sight-threatening uveitis at presentation together with high-dose intravenous corticosteroids (CSs) [7]; however, they suggested only AZA and CsA as the first-line therapy for posterior uveitis or panuveitis together with oral CSs, whereas 
IFX, ADA or IFN-alpha were indicated in refractory and/or recurrent cases [7]. Bettiol et al. reported that increasing observational evidence supports the use of IFX and ADA as second-line therapy in both ocular- and neuro-BD [42].

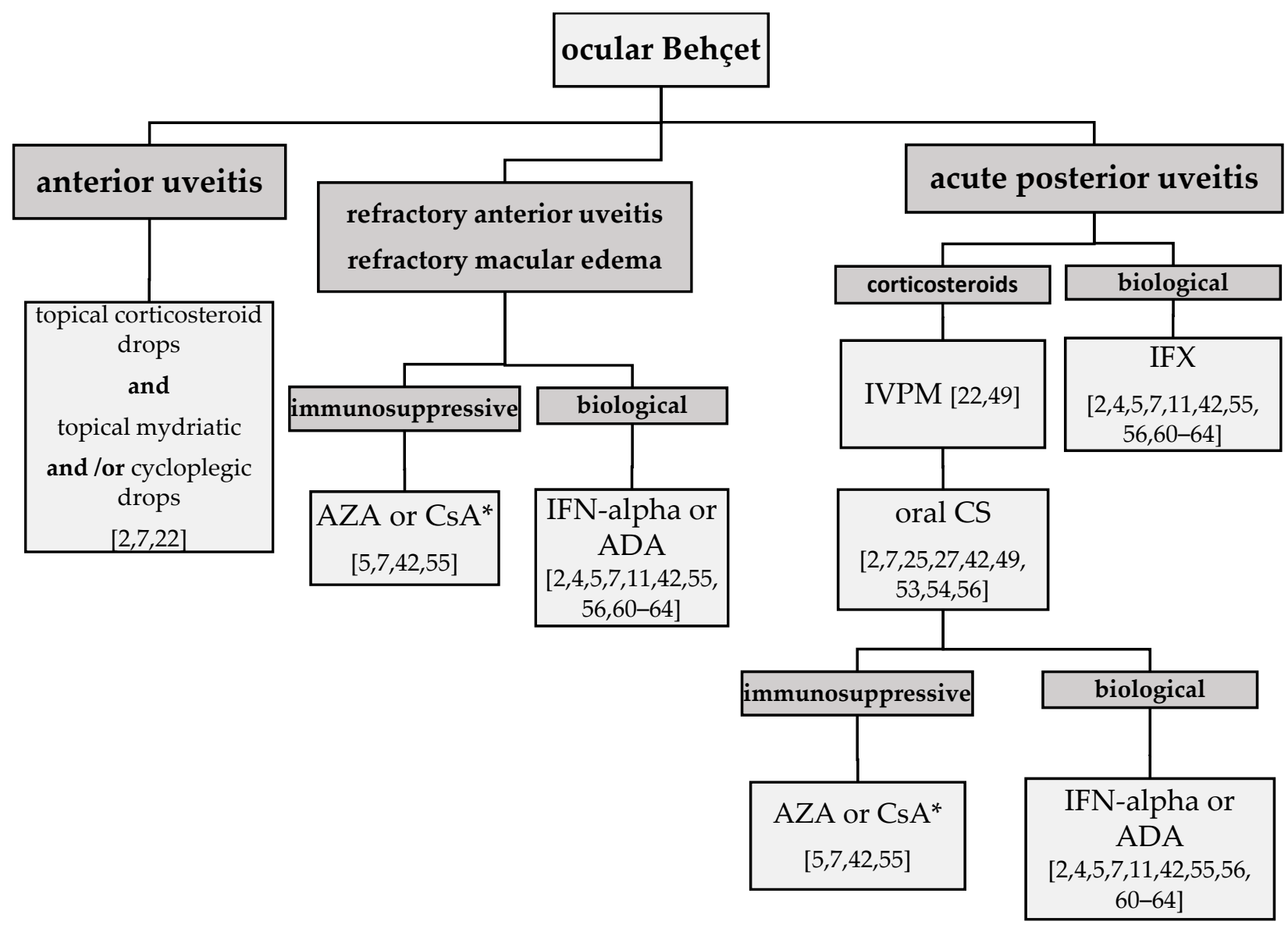

Figure 3. Proposed choice of therapeutic options, depending on the localization and severity of ocular inflammation. AZA—azathioprine; CsA—cyclosporine A $\left(^{*}\right)$-NOT in the parenchymal neurological and ocular phenotype [42,57,58]; IFN-alpha—interferon alpha; ADA—adalimumab; IFX—infliximab; IVPM—intravenous pulse methyl prednisolone; CS-corticosteroid.

IFX is administered intravenously in a loading dose of $3-5 \mathrm{mg} / \mathrm{kg}$ (0-2-6 weeks), followed by a maintenance dose every $4-8$ weeks $[4,7,59,66-69]$. The optimization of the IFX therapy is recommended after at least 12 months, once the ocular remission has been achieved for 3-6 months. It can be introduced either by gradually prolonging the dosing intervals or by reducing the dose to $3 \mathrm{mg} / \mathrm{kg}$ every eight weeks and then prolonging the dosing intervals. Treatment should be discontinued once an interval of 12 weeks has been achieved in the absence of ocular inflammation. Therapy should be restarted in case of a relapse (5 mg/kg i.v. every eight weeks) [67]. According to Markomichelakis et al., intravenous IFX should always be considered in patients with panuveitis attack in BD. They noted a significantly faster decrease of the ocular inflammation after a single IFX infusion, compared to intravenous and intra-vitreal CSs. IFX was superior to CSs in the regression of cystoid macular oedema, retinal vasculitis, and retinitis; however the improvement of visual acuity was comparable in all three treatment modalities [60].

IFX has been shown to significantly improve the BCVA [56], lower the frequency of ocular attacks [67-69] and retinal vasculitis [66,69], and furthermore reduce the central macular thickness in patients with severe posterior uveitis [4]. Nevertheless, IFX seems to have no advantage over conventional immunosuppressive therapies in preventing macular complications $[69,70]$. Initiating IFX therapy within the first 18 months of the uveoretinitis 
onset is more efficient in preserving the BCVA than after 18 months. For this reason, it is advised to switch soon after admission if the patient presents with a severe ocular involvement [71].

Yalcindag et al. recommend IFX as a first line agent in treating acute sight-threatening uveitis [4]. Horiguchi et al. did not reveal any difference between IFX monotherapy and combination therapy in their 10-year follow-up study [68]. They concluded, however, that a high study retention rate after six years of the treatment may be caused by the development of the anti-IFX antibodies, followed by a secondary inefficacy of IFX after six to ten years, which should be taken into consideration in a long-term therapy [4,68]. IFX has a rapid onset of action in comparison to the IFN-alpha [7].

ADA is the first and only non-corticosteroid agent approved by the Food and Drug Administration in the treatment of noninfectious intermediate, posterior, and panuveitis [61]. ADA is claimed to be the best immunomodulatory drug that efficiently controls noninfectious uveitis over the long term [61]. ADA (40 mg s.c. every other week) is believed to preserve visual acuity $[7,63,66]$, reduce the central macular thickness (CMT) and decrease the activity of retinal vasculitis [63]. In a study by Fabiani et al., 64\% of the patients presented a resolution of retinal vasculitis in FA after three months of therapy, and 95\% were free of active vasculitis after 12 months [63]. The authors state that their findings support the use of anti-TNF agents as the first-line therapy in severe BU [63], which stands in line with the recommendation of American Academy of Ophthalmology [65]. Combination therapy with ADA and immunosuppressive agents seems to have no advantage over ADA monotherapy [63]. ADA appears to induce better improvement of BCVA, vitritis and anterior chamber inflammation than IFX after one year of treatment of refractory BU [66].

Anti-TNFs reduce the optic disc and vascular leakage $[4,7,9]$ and enable a gradual reduction of systemic CSs until either discontinuation or low maintenance dose $[7,9,63,66]$. Patients should be screened for tuberculosis and demyelinating disease prior to the use of ADA and IFX, as those diseases may activate during immunosuppressive treatment $[2,4,5,7,64,66]$. Alongside an increased risk of infection, the most common adverse effects of the anti-TNFs are mild local reactions to infusions or subcutaneous injections [4].

Interferon alpha (IFN-alpha) is implied to be an effective second-line treatment for refractory and/or recurrent cases [2,7,37,55,56,63,64].

Celiker et al. used an algorithm where IFN-alpha is a second line treatment and anti-TNFs are used in case of IFN-alpha inefficacy [5]. In their study, $41.3 \%$ of patients had to be treated with biological agents to prevent vision loss. [5] The failure of one anti-TNF does not exclude a successful response to another anti-TNF [5,63].

IFN-alpha is composed of several proteins extracted from a leukocyte fraction of human blood that have immunomodulating properties. It is considered a second line treatment due to its side effects and costs; however, it has been proven effective in treating mid-term and long-term ocular manifestations [11,48,56,64]. IFN-alpha is reported in the literature to be administered subcutaneously in a dose of 3-18 million units, 3-7 times per week $[4,7,11,53,64,71]$, achieving a response rate from $75 \%$ to $92 \%[4,53,64]$. It is efficient within two to four weeks after initiation [11]. Shi et al. reported a significant decrease of the relapse rate to 0 per patient/year in a mean follow-up time of $21.7 \pm 7.5$ months after the following treatment: 3 million units daily for four weeks, then 3 million units every other day for three to four months, further tailored according to response [64]. Yalcindag et al. have administered 3 million units in female and low body weight patients and 4.5 million units in others. They increased the dose to 6 million units in recurrent or recalcitrant cases. BCVA improved in $87.8 \%$ of the cases [4]. Diwo et al. reported a reaction to IFN-alpha in $86.1 \%$ of the patients with severe posterior uveitis in their study, whereas $69.4 \%$ never relapsed [11]. Their study revealed a steady decrease of the CME after initiation of IFNalpha therapy during the first four years of treatment, with no relapses for nine years overall [11].

IFN-alpha is potentially beneficial for refractory neuro-BD, which makes it a reasonable choice for the ocular and parenchymal neurological phenotype [42]. It reduces optic 
disc and vascular leakage, relapse frequency, anterior segment inflammation, vitreous haze, retinal vasculitis and retinitis $[4,11]$. A long remission rate, even after discontinuation, seems to be an advantage of IFN alpha therapy over anti-TNF [11]. The most common side effects of IFN-alpha are flu-like symptoms $(88-100 \%)$ [5,11,53,64], fatigue [11], myalgia [11], leucopenia $[53,64]$ and depression $[5,11,53]$. The flu-like symptoms are a sign of the absence of the anti-IFN antibodies [4]. Four to eight percent of patients discontinue treatment due to side effects [11]. IFN retinopathy is formally impossible to differentiate from Behçet's infiltrates [11].

In the study of Yalcindag et al., no difference between the outcomes of treatment with IFX and IFN-alpha was revealed-both were proven to equally control ocular inflammation [4]. Interestingly, patients that were non-responders to IFN-alpha did not have any uveitis relapses after switching to IFX [4].

An alternative use of other biologics has been reported that needs further investigation: tacrolimus [7], tocilizumab [37] (i.v. $8 \mathrm{mg} / \mathrm{kg} / 4$ weeks) [7], golimumab [7], anakinra (s.c. $100 \mathrm{mg} /$ daily) [7], canakinumab (s.c. $150 \mathrm{mg} / 6$ weeks) [7] and rituximab [56]. Daclizumab was shown to be ineffective in BU [56]. A high withdrawal rate from the studies using gevokizumab may suggest its inefficacy, but this needs further validation [56].

\section{Discussion}

The etiopathogenesis of BD continues to be understood as a heterogenous concept, with several novel divisions reported in the literature. Shahram et al. suggest a separate pathway of development for ocular and extra-ocular types of BD after analyzing symptom patterns among different ethnic groups [14], while Hussein et al. pointed out a possibility of separate immunological variants with central and peripheral impact based on the higher severity of ocular manifestations in patients who fulfill fewer systemic criteria of BD [21]. Bettiol et al. have correlated parenchymal neurological and ocular symptoms based on literature research and have proposed to consider those patients as one phenotype and therefore adjust the treatment algorithm [42]. Nevertheless, another study on a Chinese cohort divided BD differently without connecting ocular and neurological BD into one cluster [52]. Further investigation of the various phenotypes of BD is recommended to revise the previous concept of $\mathrm{BD}$ management. Researchers suggest that the treatment of $B D$ requires a multidisciplinary approach and should be planned according to the correlated groups of symptoms which will improve the general outcome, instead of focusing on each manifestation separately [24,42,52].

An early diagnosis is necessary to prevent permanent vision loss, as BU responds to a specific immunosuppressive algorithm. SD OCT, EDI OCT, OCTA, PNFL OCT and FA enable the detection of CME and retinal neovascularization, as well as the subclinical inflammatory process in patients with systemic symptoms characteristic of $\mathrm{BD}$ and, hence, the introduction of appropriate medication $[2,6,28,31,32,34-36]$. UWF captions of color photography and FA contribute to better assessment of necessary treatment adjustments [37]. Laser flare-cell photometry has been suggested to be a reliable tool in the monitoring of ocular inflammation in BU $[38,39]$. Even though FA remains the gold standard in terms of the monitoring of ocular inflammation in $\mathrm{BU}$, the abovementioned noninvasive diagnostic tools may enable a decrease in the number of FA acquisitions and, moreover, may provide objective, quantitative indices of ocular inflammation. CMT, MV [28] and choroidal thickness [34] were reported to increase during an active inflammation. CMT has been reported to decrease below the normal values in the remission periods, which was significantly correlated to the number of uveitis attacks, which can be an indicator of a permanent damage to the retina [28]. Furthermore, CMT and MV have reduced in response to treatment in active uveitis, which supports the role of SD OCT as a monitoring tool [28]. Chams et al. revealed a fluorescein leakage in the FA in $44 \%$ of their patients with BD with no signs of ocular inflammation, indicating the value of FA for early detection of retinal vasculitis [31].

Behçet's disease ocular attack score 24 [47] and total vascular leakage score [29] have been newly proposed as effective tools to facilitate the evaluation of $\mathrm{BD}$ along the course of 
the disease. Inhomogeneity of the criteria used to describe the activity of BD among study groups seems to be a limitation to this review. Development of an objective and universal scale of BD activity would facilitate the comparison of results between physicians, and therefore further investigations seem advisable.

AZA has been long considered the first line agent, followed by CSs, ADA, IFX, IFN-alpha and CYC in variations according to the disease activity and reaction to therapy $[4,7,11,42,55,56,63,64,66-69]$; however, the role of immunomodulatory therapy has grown, due to the clinical evidence of its efficacy [60,64-71]. The American Academy of Ophthalmology has strongly recommended IFX and ADA as both first and second line of corticosteroid-sparing therapy of BU [65], which stands in line with findings of other researchers [60-64,68]. CSs should be always accompanied by other immunosuppressive agents to achieve the steroid-sparing effect $[2,7,25,27,54-56]$. Intravitreal and periocular CS injections [14,55] and dexamethasone intravitreal implants [30] are additional investigated options of local treatment. The indications to the use of CsA in BU should be reviewed due to the suggested coexistence of ocular and neurological manifestations and the neurological side-effects of CsA [37,57,58], which is in contrast to The European Alliance of Associations for Rheumatology recommendations from 2018 [55]. A limitation to this study is the inclusion of both RCTs and unrandomized clinical studies, leading to a lower reliability of the analyzed diagnostic and therapeutic solutions. There is no strict consensus on the treatment of the ocular BD, and for this reason there is a great need for randomized controlled trials to objectively compare treatment algorithms.

Author Contributions: Conceptualization, A.T.-K. and H.Z.; methodology, A.T.-K.; software, H.Z.; validation, formal analysis, A.T.-K.; investigation, H.Z.; resources, A.T.-K.; data curation, A.T.-K. and H.Z.; writing—original draft preparation, H.Z.; writing—review and editing, A.T.-K.; visualization, H.Z.; supervision, A.T.-K.; project administration, A.T.-K.; funding acquisition, not applicable. All authors have read and agreed to the published version of the manuscript.

Funding: The publication grant, intended to cover all publication fees, was funded by the Wroclaw Medical University Subvention for the Department of Ophthalmology (grant no. SUB.C240.21.036); no payment was received for authorship of the document.

Data Availability Statement: Not applicable.

Conflicts of Interest: The authors declare no conflict of interest.

\section{References}

1. Accorinti, M.; Pesci, F.R.; Pirraglia, M.P.; Abicca, I.; Pivetti-Pezzi, P. Ocular Behçet's Disease: Changing Patterns Over Time, Complications and Long-Term Visual Prognosis. Ocul. Immunol. Inflamm. 2017, 25, 29-36. [CrossRef] [PubMed]

2. Özdal, P. Çakar Behçet's Uveitis: Current Diagnostic and Therapeutic Approach. Turk. J. Ophthalmol. 2020, 50, 169-182. [CrossRef] [PubMed]

3. Bowling, B. Choroba behçeta. In Kanski Okulistyka Kliniczna; Elsevier: Sydney, NSW, Australia, 2016; pp. $424-426$.

4. Yalçindag, N.; Köse, H.C. Comparison of the Treatment Results for Behçet Uveitis in Patients Treated with Infliximab and Interferon. Ocul. Immunol. Inflamm. 2020, 28, 305-314. [CrossRef]

5. Celiker, H.; Kazokoglu, H.; Direskeneli, H. Conventional immunosuppressive therapy in severe Behcet's Uveitis: The switch rate to the biological agents. BMC Ophthalmol. 2018, 18, 1-7. [CrossRef]

6. Nida Sen, H.; Albini, T.A.; Burkholder, B.M.; Dahr, S.S.; Dodds, E.M.; Leveque, T.K.; Smith, W.M.; Vasconcelos-Santos, D.M. Behcet disease. In Uveitis and Ocular Inflammation. Basic Ophthalmology Science Course 2019-2020; American Academy of Ophthalmology: San Francisco, CA, USA, 2019; pp. 233-243.

7. Karadag, O.; Bolek, E.C. Management of Behcet's syndrome. Rheumatology 2020, 59, iii108-iii117. [CrossRef] [PubMed]

8. Posarelli, C.; Maglionico, M.N.; Talarico, R.; Covello, G.; Figus, M. Behçet's syndrome and ocular involvement: Changes over time. Clin. Exp. Rheumatol. 2020, 38, 86-93. [PubMed]

9. Tugal-Tutkun, I.; Gupta, V.; Cunningham, E.T. Differential Diagnosis of Behçet Uveitis. Ocul. Immunol. Inflamm. 2013, 21, 337-350. [CrossRef]

10. Kitaichi, N.; Miyazaki, A.; Iwata, D.; Ohno, S.; Stanford, M.R.; Chams, H. Ocular features of Behcet's disease: An international collaborative study. Br. J. Ophthalmol. 2007, 91, 1579-1582. [CrossRef]

11. Diwo, E.; Gueudry, J.; Saadoun, D.; Weschler, B.; LeHoang, P.; Bodaghi, B. Long-term Efficacy of Interferon in Severe Uveitis Associated with Behçet Disease. Ocul. Immunol. Inflamm. 2017, 25, 76-84. [CrossRef]

12. Kotulska, A.; Kucharz, E.J.; Kopec, M. Behçet's disease in Poland. Clin. Rheumatol. 2005, 24, 667-668. [CrossRef] 
13. Mahr, A.; Maldini, C. Épidémiologie de la maladie de Behçet. Revue Méd. Interne 2014, 35, 81-89. [CrossRef]

14. Shahram, F.; Mæhlen, M.T.; Akhlaghi, M.; Davatchi, F.; Liao, Y.J.; Weyand, C.M. Geographical variations in ocular and extra-ocular manifestations in Behçet's disease. Eur. J. Rheumatol. 2019, 6, 199-206. [CrossRef] [PubMed]

15. Papoutsis, N.G.; Abdel-Naser, M.B.; Altenburg, A.; Orawa, H.; Kötter, I.; Krause, L.; Pleyer, U.; Djawari, D.; Stadler, R.; Wollina, U.; et al. Prevalence of Adamantiades-Behçet's disease in Germany and the municipality of Berlin: Results of a nationwide survey. Clin. Exp. Rheumatol. 2006, 24, 125.

16. Horie, Y.; Meguro, A.; Ohta, T.; Lee, E.B.; Namba, K.; Mizuuchi, K.; Iwata, D.; Mizuki, N.; Ota, M.; Inoko, H.; et al. HLA-B51 Carriers are Susceptible to Ocular Symptoms of Behçet Disease and the Association between the Two Becomes Stronger towards the East along the Silk Road: A Literature Survey. Ocul. Immunol. Inflamm. 2015, 25, 37-40. [CrossRef] [PubMed]

17. Gül, A.; Uyar, F.A.; Inanc, M.; Öcal, L.; Tugal-Tutkun, I.; Aral, O.; Koniçe, M.; Saruhan-Direskeneli, G. Lack of association of HLA-B $* 51$ with a severe disease course in Behcet's disease. Rheumatology 2001, 40, 668-672. [CrossRef] [PubMed]

18. Kato, H.; Takeuchi, M.; Horita, N.; Ishido, T.; Mizuki, R.; Kawagoe, T.; Shibuya, E.; Yuda, K.; Ishido, M.; Mizuki, Y.; et al. HLA-A26 is a risk factor for Behçet's disease ocular lesions. Mod. Rheumatol. 2021, 31, 214-218. [CrossRef]

19. Mahr, A.; Belarbi, L.; Wechsler, B.; Jeanneret, D.; Dhote, R.; Fain, O.; Lhote, F.; Ramanoelina, J.; Coste, J.; Guillevin, L. Populationbased prevalence study of Behçet's disease: Differences by ethnic origin and low variation by age at immigration. Arthritis Rheum. 2008, 58, 3951-3959. [CrossRef]

20. Kötter, I.; Vonthein, R.; Gûnaydin, I.; Müller, C.; Kanz, L.; Zierhut, M.; Stübiger, N. Behçet's Disease in Patients of German and Turkish Origin-A Comparative Study. Results Probl. Cell Differ. 2003, 528, 53-58. [CrossRef]

21. Hussein, M.A.; Eissa, I.M.; Dahab, A.A. Vision-Threatening Behcet's Disease: Severity of Ocular Involvement Predictors. J. Ophthalmol. 2018, 2018, 1-6. [CrossRef]

22. Evereklioglu, C. Current Concepts in the Etiology and Treatment of Behçet Disease. Surv. Ophthalmol. 2005, 50, 297-350. [CrossRef]

23. Leccese, P.; Alpsoy, E. Behçet's Disease: An Overview of Etiopathogenesis. Front. Immunol. 2019, 10, 1-8. [CrossRef] [PubMed]

24. Hussein, M.A.; Ellawindi, M.I.; Ragab, G. Performance of classification criteria for Behcet's disease in an Egyptian cohort. Indian J. Rheumatol. 2017, 12, 152. [CrossRef]

25. Yazici, H.; Seyahi, E.; Hatemi, G.; Yazici, Y. Behçet syndrome: A contemporary view. Nat. Rev. Rheumatol. 2018, 14, 107-119. [CrossRef] [PubMed]

26. Gürlü, V.; Güçlü, H.; Özal, A. Thickness Changes in Foveal, Macular, and Ganglion Cell Complex Regions Associated with Behçet Uveitis during Remission. Eur. J. Ophthalmol. 2015, 26, 347-350. [CrossRef] [PubMed]

27. Tugal-Tutkun, I.; Onal, S.; Stanford, M.; Akman, M.; Twisk, J.W.; Boers, M.; Oray, M.; Özdal, P.Ç.; Kadayifcilar, S.; Amer, R.; et al. An Algorithm for the Diagnosis of Behçet Disease Uveitis in Adults. Ocul. Immunol. Inflamm. 2020, 1-10. [CrossRef]

28. Kang, H.M.; Koh, H.J.; Lee, S.C. Spectral domain optical coherence tomography as an adjunctive tool for screening Behçet uveitis. PLoS ONE 2018, 13, e0208254. [CrossRef]

29. Keino, H. Evaluation of disease activity in uveoretinitis associated with Behçet's disease. Immunol. Med. 2021, 44, 86-97. [CrossRef] [PubMed]

30. Yalcinbayir, O.; Caliskan, E.; Gunduz, G.U.; Gelisken, O.; Kaderli, B.; Yucel, A.A. Efficacy of Dexamethasone Implants in Uveitic Macular Edema in Cases with Behçet Disease. Ophthalmology 2019, 241, 190-194. [CrossRef]

31. Chams, H.; Mohtasham, N.; Davatchi, F.; Shahram, F.; Naji, A.; Harandi, Z.A.; Karimi, N. Ophthalmic findings in Behcet's disease: Cases without apparent ocular signs. J. Curr. Ophthalmol. 2015, 27, 46-50. [CrossRef]

32. Tugal-Tutkun, I.; Ozdal, P.C.; Oray, M.; Onal, S. Review for Diagnostics of the Year: Multimodal Imaging in Behçet Uveitis. Ocul. Immunol. Inflamm. 2017, 25, 7-19. [CrossRef]

33. Tugal-Tutkun, I.; Onal, S.; Özyazgan, Y.; Soylu, M.; Akman, M. Validity and Agreement of Uveitis Experts in Interpretation of Ocular Photographs for Diagnosis of Behçet Uveitis. Ocul. Immunol. Inflamm. 2013, 22, 461-468. [CrossRef]

34. Chung, Y.-R.; Cho, E.H.; Jang, S.; Lee, S.Y.; Lee, E.-S.; Lee, K. Choroidal Thickness Indicates Subclinical Ocular and Systemic Inflammation in Eyes with Behçet Disease without Active Inflammation. Korean J. Ophthalmol. 2018, 32, 290-295. [CrossRef]

35. Emre, S.; Güven-Yılmaz, S.; Ulusoy, M.O.; Ateş, H. Optical coherence tomography angiography findings in Behcet patients. Int. Ophthalmol. 2019, 39, 2391-2399. [CrossRef]

36. Zarei, M.; Pesarakli, H.; Yaseri, M.; Etesali, H.; Ebrahimiadib, N. Peripapillary optical coherence tomography as an alternative to fluorescein angiography for monitoring Behcet's retinal vasculitis. Sci. Rep. 2021, 11, 1-8. [CrossRef]

37. Leder, H.A.; Campbell, J.P.; Sepah, Y.J.; Gan, T.; Dunn, J.P.; Hatef, E.; Cho, B.; Ibrahim, M.; Bittencourt, M.; Channa, R.; et al. Ultra-wide-field retinal imaging in the management of non-infectious retinal vasculitis. J. Ophthalmic Inflamm. Infect. 2013, 3, 30. [CrossRef]

38. Tugal-Tutkun, I.; Herbort, C.P. Laser flare photometry: A noninvasive, objective, and quantitative method to measure intraocular inflammation. Int. Ophthalmol. 2010, 30, 453-464. [CrossRef] [PubMed]

39. Tugal-Tutkun, I.; Cingü, K.; Kir, N.; Yeniad, B.; Urgancioglu, M.; Gül, A. Use of laser flare-cell photometry to quantify intraocular inflammation in patients with Behçet Uveitis. Graefe's Arch. Clin. Exp. Ophthalmol. 2008, 246, 1169-1177. [CrossRef] [PubMed]

40. Kardum, Ž.; Ahić, J.M.; Lukinac, A.M.; Ivelj, R.; Prus, V. Optic neuritis as a presenting feature of Behçet's disease: Case-based review. Rheumatol. Int. 2021, 41, 189-195. [CrossRef] [PubMed] 
41. Mahgoub, M.Y.; Elmohamady, M.N. Consistency of Visual Evoked Potential in Extraocular Manifestationsof Behcet Disease and Impact of Corticosteroid Treatment. J. Clin. Neurophysiol. 2019, 38, 43-46. [CrossRef] [PubMed]

42. Bettiol, A.; Hatemi, G.; Vannozzi, L.; Barilaro, A.; Prisco, D.; Emmi, G. Treating the Different Phenotypes of Behçet's Syndrome. Front. Immunol. 2019, 10, 2830. [CrossRef]

43. Cankaya, C.; Kalayci, B.N. Corneal Biomechanical Characteristics in Patients with Behcet Disease. Semin. Ophthalmol. 2016, 31, 439-445. [CrossRef] [PubMed]

44. Ozbek-Uzman, S.; Sungur, G.K.; Yalniz-Akkaya, Z.; Orman, G.; Burcu, A.; Ornek, F. Anterior segment parameters in Behçet's patients with ocular involvement. Int. Ophthalmol. 2020, 40, 1387-1395. [CrossRef] [PubMed]

45. Demircan, E.; Citirik, M.; Berker, N.; Unverdi, H.; Hucumenoglu, S. Conjunctival Cytological Alterations in Ocular Behçet Disease. Cornea 2016, 35, 1454-1458. [CrossRef] [PubMed]

46. Karaca, I.; Palamar, M.; Yilmaz, S.G.; Ates, H. Evaluation of Ocular Surface and Meibomian Glands Alterations with Meibography in Patients with Inactive Behçet's Uveitis. Curr. Eye Res. 2018, 44, 356-359. [CrossRef] [PubMed]

47. Tanaka, R.; Murata, H.; Takamoto, M.; Ohtomo, K.; Okinaga, K.; Yoshida, A.; Kawashima, H.; Nakahara, H.; Fujino, Y.; Kaburaki, T. Behçet's disease ocular attack score 24 and visual outcome in patients with Behçet's disease. Br. J. Ophthalmol. 2015, 100, 990-994. [CrossRef] [PubMed]

48. Herbort, C.P.; Rao, N.A.; Mochizuki, M. The Members of The Scientific members of Scientific Committee of First International Workshop on Ocular Sarcoidosis International Criteria for the Diagnosis of Ocular Sarcoidosis: Results of the First International Workshop on Ocular Sarcoidosis (IWOS). Ocul. Immunol. Inflamm. 2009, 17, 160-169. [CrossRef]

49. Gupta, A.; Bansal, R.; Gupta, V.; Sharma, A.; Bambery, P. Ocular Signs Predictive of Tubercular Uveitis. Am. J. Ophthalmol. 2010, 149, 562-570. [CrossRef]

50. Margo, C.E.; Hamed, L.M. Ocular syphilis. Surv. Ophthalmol. 1992, 37, 203-220. [CrossRef]

51. Bitik, B.; Tufan, A.; Sahin, K.; Karadag, Y.S.; Sandikci, S.C.; Mercan, R.; Ak, F.; Karaaslan, Y.; Ozturk, M.A.; Goker, B.; et al. The association between the parenchymal neurological involvement and posterior uveitis in Behçet's syndrome. Clin. Exp. Rheumatol. 2016, 34, 82-85.

52. Zou, J.; Luo, J.-F.; Shen, Y.; Cai, J.-F.; Guan, J.-L. Cluster analysis of phenotypes of patients with Behçet's syndrome: A large cohort study from a referral center in China. Arthritis Res. 2021, 23, 1-9. [CrossRef]

53. Hasanreisoglu, M.; Cubuk, M.O.; Ozdek, S.; Gurelik, G.; Aktas, Z.; Hasanreisoglu, B. Interferon Alpha-2a Therapy in Patients with Refractory Behçet Uveitis. Ocul. Immunol. Inflamm. 2017, 25, 71-75. [CrossRef]

54. Yalçindâ,, F.N.; Can, E.; Özdemir, Ö. Intravenous Methylprednisolone Pulse Therapy for Acute Posterior Segment Uveitis Attacks in Behçet's Disease. Ann. Ophthalmol. 2007, 39, 194-197. [CrossRef]

55. Hatemi, G.; Robin, C.; Bang, D.; Bodaghi, B.; Celik, A.F.; Fortune, F.; Gaudric, J.; Gul, A.; Kötter, I.; Lecesse, P.; et al. 2018 update of the EULAR recommandations for the management of Behçet's syndrome. Ann. Rheum. Dis. 2018, 77, 808-818. [PubMed]

56. Uke, P.; Gorodkin, R.; Beare, N. Biologic therapy for Behçet's uveitis: A systematic review. Br. J. Ophthalmol. 2020, 104, 1045-1051. [CrossRef] [PubMed]

57. Akman-Demir, G.; Ayranci, O.; Kurtuncu, M.; Vanli, E.N.; Mutlu, M.; Tugal-Tutkun, I.; Expand, A. Cyclosporine for Behçet's uveitis: Is it associated with an increased risk of neurological in-volvement? Clin. Exp. Rheumatol. 2008, 26, 84-90.

58. Kötter, I.; Günaydin, I.; Batra, M.; Vonthein, R.; Stübiger, N.; Fierlbeck, G.; Melms, A. CNS involvement occurs more frequently in patients with Behçet's disease under cyclosporin A (CSA) than under other medications-Results of a retrospective analysis of 117 cases. Clin. Rheumatol. 2005, 25, 482-486. [CrossRef] [PubMed]

59. Foster, C.S.; Kothari, S.; Anesi, S.D.; Vitale, A.T.; Chu, D.; Metzinger, J.L.; Cerón, O. The Ocular Immunology and Uveitis Foundation preferred practice patterns of uveitis management. Surv. Ophthalmol. 2016, 61, 1-17. [CrossRef]

60. Markomichelakis, N.; Delicha, E.; Masselos, S.; Fragiadaki, K.; Kaklamanis, P.; Sfikakis, P.P. A single infliximab infusion vs corticosteroids for acute panuveitis attacks in Behcet's disease: A comparative 4-week study. Rheumatology 2011, 50, 593-597. [CrossRef]

61. Duica, I.; Voinea, L.-M.; Mitulescu, C.; Istrate, S.; Coman, I.-C.; Ciuluvica, R. The use of biologic therapies in uveitis. Romanian J. Ophthalmol. 2018, 61, 105-113. [CrossRef]

62. Thomas, A.S. Biologics for the treatment of noninfectious uveitis. Curr. Opin. Ophthalmol. 2019, 30, 138-150. [CrossRef]

63. Fabiani, C.; Vitale, A.; Emmi, G.; Vannozzi, L.; Lopalco, G.; Guerriero, S.; Orlando, I.; Franceschini, R.; Bacherini, D.; Cimino, L.; et al. Efficacy and safety of adalimumab in Behçet's disease-related uveitis: A multicenter retrospective observational study. Clin. Rheumatol. 2017, 36, 183-189. [CrossRef]

64. Shi, J.; Zhao, C.; Zhou, J.; Liu, J.; Wang, L.; Gao, F.; Zeng, X.; Zhang, M.; Zheng, W. Effectiveness and safety of interferon $\alpha 2 a$ as an add-on treatment for refractory Behçet's uveitis. Ther. Adv. Chronic Dis. 2019, 10, 1-9. [CrossRef]

65. Levy-Clarke, G.; Jabs, D.A.; Read, R.W.; Rosenbaum, J.T.; Vitale, A.; Van Gelder, R.N. Expert Panel Recommendations for the Use of Anti-Tumor Necrosis Factor Biologic Agents in Patients with Ocular Inflammatory Disorders. Ophthalmology 2014, 121, 785-796.e3. [CrossRef] [PubMed]

66. Atienza-Mateo, B.; Martin-Varillas, J.L.; Calvo-Rio, V.; Demetrio-Pablo, R.; Beltran, E.; Sanchez-Burson, J.; Mesquida, M.; Adan, A.; Hernandez, M.V. Comparative Study of Infliximab Versus Adalimumab in Refractory Uveitis due to Behçet's Disease National Multicenter Study of 177 Cases. Arthritis Rheumatol. 2019, 71, 2081-2089. [CrossRef] 
67. Martín-Varillas, J.L.; Atienza-Mateo, B.; Calvo-Rio, V.; Beltrán, E.; Sánchez-Bursón, J.; Adán, A.; Hernández-Garfella, M.; VallsPascual, E.; Sellas-Fernández, A.; Ortego, N.; et al. Long-term Follow-up and Optimization of Infliximab in Refractory Uveitis Due to Behçet Disease: National Study of 103 White Patients. J. Rheumatol. 2021, 48, 741-750. [CrossRef]

68. Horiguchi, N.; Kamoi, K.; Horie, S.; Iwasaki, Y.; Kurozumi-Karube, H.; Takase, H.; Ohno-Matsui, K. A 10-year follow-up of infliximab monotherapy for refractory uveitis in Behçet's syndrome. Sci. Rep. 2020, 10, 1-10. [CrossRef]

69. Tugal-Tutkun, I.; Mudun, A.; Urgancioglu, M.; Kamali, S.; Kasapoglu, E.; Inanc, M.; Gül, A. Efficacy of infliximab in the treatment of uveitis that is resistant to treatment with the combination of azathioprine, cyclosporine, and corticosteroids in behçet's disease: An open-label trial. Arthritis Rheum. 2005, 52, 2478-2484. [CrossRef] [PubMed]

70. Sota, J.; Cantarini, L.; Vitale, A.; Sgheri, A.; Gentileschi, S.; Caggiano, V.; Gelardi, V.; Frediani, B.; Tosi, G.M.; Fabiani, C. Long-Term Outcomes of Behçet's Syndrome-Related Uveitis: A Monocentric Italian Experience. Mediat. Inflamm. 2020, 2020, 1-8. [CrossRef] [PubMed]

71. Keino, H.; Watanabe, T.; Nakayama, M.; Komagata, Y.; Fukuoka, K.; Okada, A. Long-term efficacy of early infliximab-induced remission for refractory uveoretinitis associated with Behçet's disease. Br. J. Ophthalmol. 2021, 105, 1525-1533. [CrossRef] 